\title{
Reducing maternal deaths by skills-and-drills training in managing obstetric emergencies: A before-and-after observational study
}

\author{
R C Pattinson, ${ }^{1,2}$ FRCOG, MD, FCOG (SA), MMed, MB BCh, BSc; A-M Bergh, ${ }^{1} \mathrm{PhD}$; \\ C Ameh, ${ }^{3} \mathrm{PhD}$, MPH, MBBS, FWACS (OBGYN), FRSPH, FRCOG; J Makin ${ }^{1,2}$ MB BCh, BSc (Epidemiology), MSc (Clinical Epidemiology); \\ Y Pillay, ${ }^{4} \mathrm{PhD}$; N van den Broek, ${ }^{3}$ PhD, FRCOG, DTM\&H, MBBS; J Moodley, ${ }^{5,6}$ MB ChB, FRCOG, FCOG (SA), MD \\ ${ }^{1}$ South African Medical Research Council Maternal and Infant Health Care Strategies Unit, Faculty of Health Sciences, University of Pretoria, South Africa \\ ${ }^{2}$ Department of Obstetrics and Gynaecology, Faculty of Health Sciences, University of Pretoria, South Africa \\ ${ }^{3}$ Centre for Maternal and Newborn Health, Liverpool School of Tropical Medicine, Pembroke Place, Liverpool, UK \\ ${ }^{4}$ Deputy Director-General: Programmes, National Department of Health, South Africa \\ ${ }^{5}$ Chairman: Emergency Obstetric Simulation Training Board, South Africa \\ ${ }^{6}$ Chairman: National Committee on Confidential Enquiries into Maternal Deaths, South Africa
}

Corresponding author: R C Pattinson (robert.pattinson@up.ac.za)

\begin{abstract}
Background. The institutional maternal mortality ratio (iMMR) in South Africa (SA) is still unacceptably high. A key recommendation from the National Committee on Confidential Enquiries into Maternal Deaths has been to improve the availability and quality of care for women suffering obstetric emergencies.

Objectives. To determine whether there was a change in the number of maternal deaths and in the iMMR over time that could be attributed to the training of $>80 \%$ of healthcare professionals by means of a specifically designed emergency obstetric care (EmOC) training programme. Methods. A before-and-after study was conducted in 12 healthcare districts in SA, with the remaining 40 districts serving as a comparison group. Twelve 'most-in-need' healthcare districts in SA were selected using a composite scoring system. Multiprofessional skills-and-drills workshops were held off-site using the Essential Steps in Managing Obstetric Emergencies and Emergency Obstetric Simulation Training programme. Eighty percent or more of healthcare professionals providing maternity care in each district were trained between October 2012 and March 2015. Institutional births and maternal deaths were assessed for the period January 2011 - December 2016 and a before-andafter-training comparison was made. The number of maternal deaths and the iMMR were used as outcome measures.

Results. A total of 3237 healthcare professionals were trained at 346 workshops. In all, 1248333 live births and 2212 maternal deaths were identified and reviewed for cause of death as part of the SA confidential enquiries. During the same period there were 5961 maternal deaths and 5439870 live births in the remaining 40 districts. Significant reductions of $29.3 \%$ in the number of maternal deaths (risk ratio (RR) $0.71,95 \%$ confidence interval (CI) $0.66-0.77$ ) and $17.5 \%$ in the number of maternal deaths from direct obstetric causes (RR 0.825 , 95\% CI 0.73 - 0.93) were recorded. When comparing the percentage change in iMMR for equivalent before-and-after periods, there was a greater reduction in all categories of causes of maternal death in the intervention districts than in the comparison districts.

Conclusions. Implementing a skills-and-drills EmOC training package was associated with a significant reduction in maternal deaths.
\end{abstract}

S Afr Med J 2019;109(4):241-245. DOI:10.7196/SAMJ.2019.v109i4.13578

South Africa (SA) has conducted confidential enquiries into maternal deaths since 1998. The 'Saving Mothers' reports have consistently documented $\sim 60 \%$ of deaths as potentially preventable. ${ }^{[1]}$ A key recommendation was to improve the availability and quality of care for women suffering obstetric emergencies. A skills-anddrills programme known as Essential Steps in Managing Obstetric Emergencies (ESMOE) was developed in 2008 to train all maternity staff. ${ }^{[2]}$ The programme is based on the Life Saving Skills - Emergency Obstetric and Newborn Care programme ${ }^{[3]}$ and was developed in collaboration with the Liverpool School of Tropical Medicine (LSTM). Funding became available in 2012 to take the training programme to scale.

A recent systematic review on the effectiveness of emergency obstetric care (EmOC) training included 118 publications, but showed that only 17 studies measured perinatal and maternal health outcomes, which are considered level 4 outcomes on an adapted Kirkpatrick training evaluation framework. Most studies included evaluation at the lower levels: 68 studies measured mentee reaction to training (level 1) or change in knowledge and skills (level 2), and 51 studies investigated change in clinical practice (level 3). The measures of impact frequently used at level 4 were neonatal mortality rate, perinatal mortality rate, case fatality rate (CFR), institutional maternal mortality ratio (iMMR), fresh stillbirth rate, stillbirth rate, maternal mortality due to postpartum haemorrhage, incidence of birth asphyxia, occurrence of neonatal complications after shoulder dystocia, and retrospective assessment of Apgar scores, stillbirth rates and hypoxic ischaemic encephalopathy (Ameh C, Mdegela M, White S, van den Broek N, 'The effectiveness of training in emergency obstetric care: A systematic literature review' - unpublished data, 2018).

\section{Objectives}

To report on the influence of the ESMOE programme on maternal deaths. 


\section{Methods \\ Study setting}

SA is divided into 52 healthcare districts with varying maternal and perinatal mortality rates. The 12 'most-in-need' districts that contributed half of the maternal deaths (outside of districts with medical schools) during the period $2008-2010^{[4]}$ were identified for intensive skills-and-drills emergency care training. The most-inneed districts were identified by developing a score using the iMMR, the number of maternal deaths and the stillbirth rate per district. Districts with the highest scores were selected for the intervention.

\section{Study design and outcome measures}

A before-and-after observational study compared maternal deaths and iMMRs in the 12 districts that had received intensive training with the results in the remaining 40 districts. The number of maternal deaths, the iMMR, the iMMR per underlying maternal condition, the caesarean delivery (CD) rate and the CFR for CD were used as outcomes.

\section{Intervention}

Off-site skills-and-drills training in EmOC was introduced and delivered over 2 days (junior midwives) or 3 days (senior midwives and all medical staff) for at least $80 \%$ of all staff involved in providing maternity services at each participating healthcare facility.

The EmOC training workshop content covers the essential knowledge and skills required by skilled birth attendants to recognise and manage the major causes of maternal and newborn death in low- and middle-income countries and includes all EmOC signal functions. Topics included were maternal and newborn resuscitation; early newborn care (recognition and management of prematurity, hypoglycaemia and hypothermia); communication triage and referral; management of shock and the unconscious patient; recognition and management of severe pre-eclampsia and eclampsia; recognition, prevention and management of obstetric haemorrhage; sepsis; use of the partograph; recognition and management of obstructed labour; ability to perform assisted vaginal delivery (ventouse delivery); manual removal of retained placenta and manual vacuum aspiration for retained products of conception; recognition and management of other obstetric emergencies (breech delivery, cord prolapse, twin delivery, shoulder dystocia); and managing difficult caesarean sections. For SA additional modules inclu- ded the recognition and management of complications in women who are HIVpositive. Similarly, monthly 'fire drills' included content similar to the above, with one skill per session covered with each drill. ${ }^{[2,3]}$ Trainees were tested on knowledge and skills before and after training. ${ }^{[5]}$

Most training took place away from the hospital or community health centre and the staff from the same institution rotated so that they could all attend the training. The implementation of the programme is described in more detail elsewhere. ${ }^{[6]}$ In each district most of the maternity and casualty staff were trained consecutively in a 2-month block starting in October 2012 and ending in March 2015.

\section{Ethics approval}

Ethics approval of the study was given by the University of Pretoria Faculty of Health Sciences Research Ethics Committee on 30 May 2012 (ref. no. 89/2012) and the ethics committees of each of the districts involved.

\section{Data collection}

Before commencing the project, a baseline assessment of each district was carried out with special reference to the availability of basic and comprehensive emergency obstetric signal functions. ${ }^{[7]}$

The National Committee on Confidential Enquiries into Maternal Deaths (NCCEMD) is responsible for the confidential enquiries into maternal deaths in SA and produces triennial reports entitled 'Saving Mothers. ${ }^{\text {[1,8] }}$ The NCCEMD records all maternal deaths that occur in health institutions in SA but does not record the facility where the death occurred, only the health district and the level of care that the institution provides. The NCCEMD gave permission for the maternal deaths occurring in the 12 districts to be extracted from the database for each month of the total training period. Data on the number of CDs and maternal deaths where a $\mathrm{CD}$ was performed were also collected and analysed. The standard classification and method used by the NCCEMD was used to classify the underlying causes of maternal death. Details of the classification are given in the 'Saving Mothers' reports. ${ }^{[1]}$ The denominator data were obtained from the District Health Information System, which falls under the National Department of Health.

\section{Data analysis}

Maternal deaths were analysed for a 6-year period from January 2011 to December 2016. Data were aggregated to represent the number of maternal deaths during the periods before and after the training. For the study sites, 'before training' refers to the period from January 2011 to the start of training. 'After training' refers to training up to December 2016. The 2 months of training in the study sites were excluded. Fig. 1 illustrates the before-and-after analysis periods for each district. For example, district 1 had a period of 21 months before training and 49 months after training, whereas district 12 had 49 months before training and 21 months after training. For the non-study sites, the 'before' period was from January 2011 to December 2013 and the 'after' period from January 2014 to December 2016. This is illustrated by the red line in Fig. 1.

For the control before-and-after groups, the births and deaths from the study group were subtracted from the overall births and maternal deaths for SA for the 6-year period. ${ }^{[1,8]}$ The period from 1 January 2011 to 31 December 2013 was used as a comparison for the 'before' period and that from 1 January 2014 to 31 December 2016

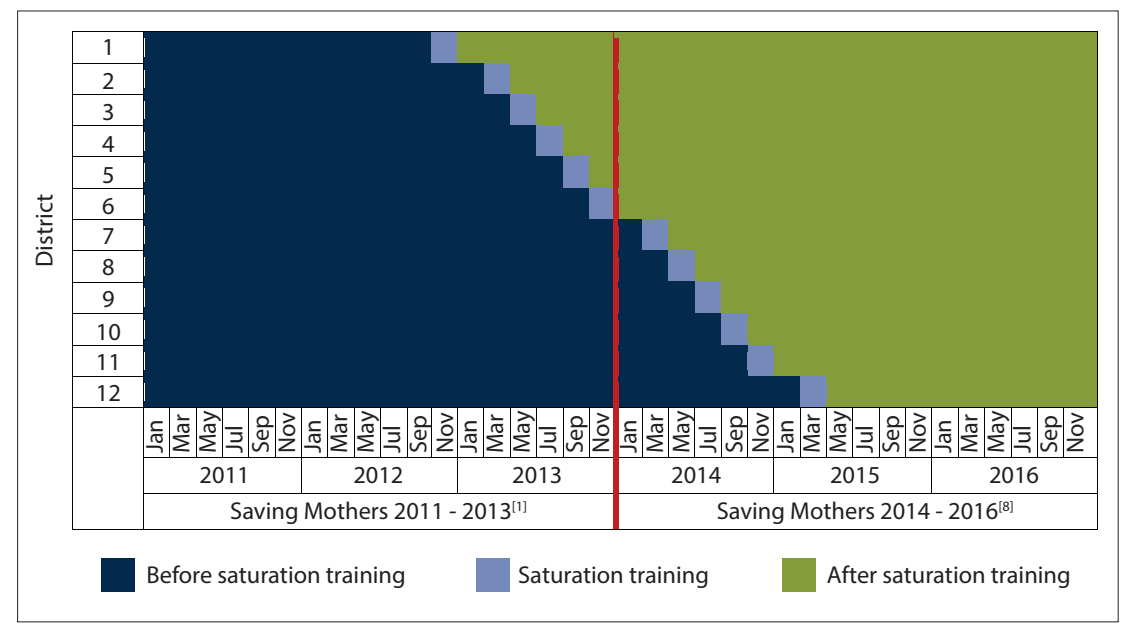

Fig. 1. Illustration of analysis of the study. 
as a comparison for the 'after' period. These two periods fell midway into the training period for the 12 districts and coincided with the 'Saving Mothers' triennial reports.

To calculate the percentage change in mortality, the difference in iMMR before training was subtracted from the iMMR after training for the study sites. For the remaining 40 districts, the iMMR for 2011 - 2013 was subtracted from the iMMR for 2014 - 2016.

\section{Results}

A total of 3237 healthcare professionals were trained (645 doctors, 303 advanced midwives, 2130 professional nurses and 159 others). During the period October 2012 - March 2015, 346 workshops were held (210 3-day and 1362 -day workshops). In the 12 targeted districts, $>80 \%$ of the healthcare professionals involved in maternity care were trained.

\section{Maternal deaths}

In total, 1248333 live births and 2212 maternal deaths were reported over the 6-year period in the 12 districts, resulting in an overall maternal mortality ratio of $177.2 / 100000$ live births. There was a significant reduction of $29.3 \%$ in the iMMR when comparing the period before with the period after training (risk ratio (RR) $0.71,95 \%$ confidence interval (CI) $0.66-0.77)$ and a $17.5 \%$ reduction in direct maternal deaths (RR $0.825,95 \%$ CI 0.73 - 0.93) (Table 1).

During the study period there were 5961 maternal deaths and 4316410 live births in the remaining 40 districts (iMMR 138.1/ 100000 live births). The iMMR for 2011 - 2013 was 143.97/100 000 live births and for 2014 - 2016 it was 132.19/100 000 live births. This represents a reduction of $8.2 \%$. There was a $2.7 \%$ increase in direct and a $19.5 \%$ reduction in indirect maternal deaths in these districts.

\section{Causes of maternal deaths}

Table 1 compares the various underlying causes of maternal deaths before and after the training intervention. There was a significant reduction in maternal deaths due to non-pregnancyrelated infections (RR $0.531,95 \%$ CI 0.456 - 0.618), medical and surgical diseases (RR 0.766, 95\% CI 0.587 - 0998), miscarriage (RR $0.683,95 \%$ CI $0.469-0.994$ ) and severe haemorrhage, i.e. obstetric haemorrhage plus ectopic pregnancies (RR 0.802, 95\%
CI 0.655 - 0.981). There was a non-significant declining trend in maternal deaths due to complications of hypertension (RR 0.862 , 95\% CI 0.697 - 1.067).

The CD rate remained constant at $24.9 \%$ before and $24.3 \%$ after the training. The CFR for women who had a CD after the staff had undergone training was $13 \%$ lower than before training. Before training the CFR was $197 / 100000 \mathrm{CDs}(345 / 174769 \mathrm{CDs})$ and after training 168/100 000 CDs (253/150 539 CDs) (RR 0.851, 95\% CI 0.724 - 1.001). The CFR for CD and for bleeding during or after $\mathrm{CD}$ was $36 \%$ lower after training. Before training it was $34 / 100000$ (60/174 $769 \mathrm{CDs})$ and after training 21/100 000 (33/150 $539 \mathrm{CDs})$ (RR 0.64, 95\% CI 0.419 - 0.972).

\section{Comparison of outcomes for intervention v. non-intervention districts}

Fig. 2 illustrates the percentage change by cause of maternal death after the introduction of ESMOE to the core districts targeted for saturation training and the remaining districts in SA. The percentage changes in mortality for direct and indirect deaths in the intervention districts were $-17.5 \%$ and $-42.0 \%$, respectively, whereas for the non-intervention districts the figures were $+2.7 \%$ and $-19.5 \%$, respectively. In all respects there was a higher percentage change in the intervention districts compared with the rest of SA. There was a reduction in death for all conditions except embolism in the core districts, whereas in the rest of SA there were increases in mortality from hypertension, ectopic pregnancy, miscarriage, embolism, and medical and surgical conditions. When comparing the percentage change in all conditions except pregnancy-related sepsis in the study districts, there was a reduction in the number of maternal deaths compared with the rest of SA.

\section{Discussion}

Saturation training in emergency skills and drills had a major impact on maternal deaths in the districts where it was conducted. The effects were not caused by a general reduction in maternal deaths. The comparison between the study districts and the rest of SA shows a much bigger reduction in deaths in the intervention group than in the rest of SA. In respect of direct maternal deaths and some underlying causes, there was an increase in the iMMR in the rest of

Table 1. Comparison of underlying causes of maternal death before and after EmOC training (data from NCCEMD per district)

\begin{tabular}{|c|c|c|c|c|c|c|c|}
\hline \multirow[b]{2}{*}{ Underlying causes } & \multicolumn{2}{|c|}{ Maternal deaths $(n)^{*}$} & \multicolumn{2}{|c|}{ iMMR } & \multirow[b]{2}{*}{$\mathbf{R R}$} & \multirow[b]{2}{*}{$95 \%$ CI } & \multirow[b]{2}{*}{$p$-value } \\
\hline & Before & After & Before & After & & & \\
\hline Indirect & 620 & 336 & 96.05 & 55.73 & 0.58 & $0.510-0.662$ & $<0.00001$ \\
\hline Medical and surgical disorders & 130 & 93 & 20.14 & 15.43 & 0.766 & $0.587-0.998$ & 0.0489 \\
\hline Non-pregnancy-related infections & 490 & 243 & 75.91 & 40.31 & 0.531 & $0.456-0.618$ & $<0.00001$ \\
\hline Direct & 621 & 475 & 96.21 & 78.79 & 0.825 & $0.733-0.930$ & 0.0015 \\
\hline Miscarriage & 69 & 44 & 10.69 & 7.30 & 0.683 & $0.469-0.994$ & 0.047 \\
\hline Pregnancy-related sepsis & 60 & 52 & 9.30 & 8.63 & 0.927 & $0.640-1.345$ & 0.693 \\
\hline $\begin{array}{l}\text { Severe haemorrhage (obstetric haemorrhage and } \\
\text { ectopic pregnancy) }\end{array}$ & 219 & 164 & 33.93 & 27.20 & 0.802 & $0.655-0.981$ & 0.032 \\
\hline Hypertension & 190 & 153 & 29.44 & 25.38 & 0.862 & $0.697-1.067$ & 0.172 \\
\hline Anaesthetic complications & 24 & 18 & 3.72 & 2.99 & 0.803 & $0.436-1.478$ & 0.481 \\
\hline Embolism & 28 & 27 & 4.34 & 4.48 & 1.032 & $0.609-1.752$ & 0.906 \\
\hline Acute collapse (cause unknown) & 31 & 17 & 4.80 & 2.82 & 0.587 & $0.327-1.053$ & 0.074 \\
\hline Unknown & 59 & 45 & 9.14 & 7.46 & 0.816 & $0.554-1.203$ & 0.305 \\
\hline Total & 1332 & 880 & 206.36 & 145.97 & 0.707 & $0.650-0.770$ & $<0.00001$ \\
\hline
\end{tabular}




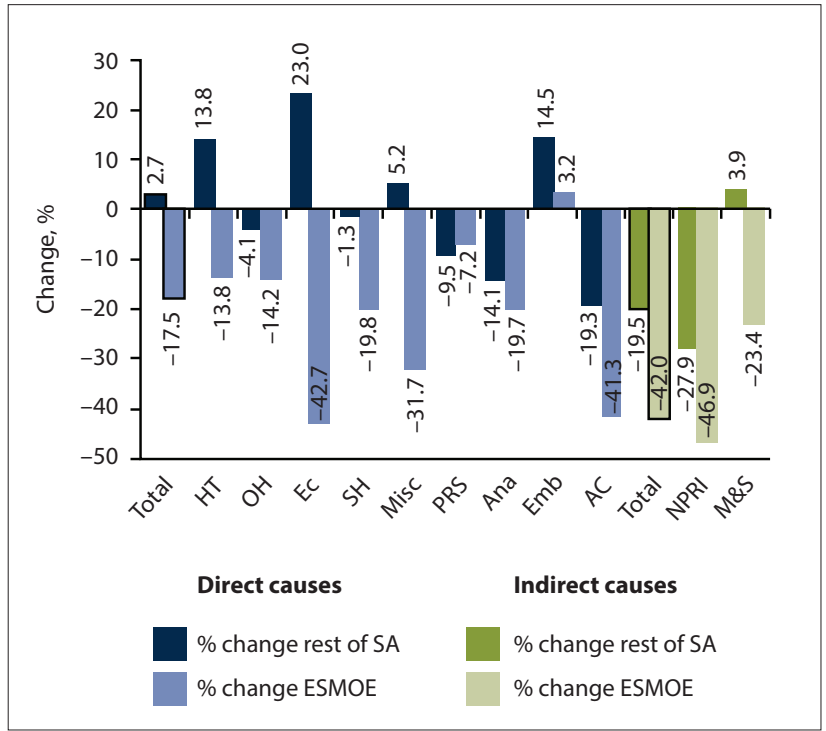

Fig. 2. Comparison of percentage changes in the ESMOE group v. the rest of $S A$, by cause of maternal death. (HT = hypertension; $\mathrm{OH}=$ obstetric haemorrhage; Ec = ectopic pregnancy; $\mathrm{SH}=$ severe haemorrhage $(\mathrm{OH}+$ ectopic); Misc = miscarriage; $P R S=$ pregnancy-related sepsis; Ana = anaesthetic complications; Emb = embolism; $A C=$ acute collapse (cause unknown); NPRI = non-pregnancy-related infections; $M \triangleleft S=$ medical and surgical disorders; $S A=$ South Africa; ESMOE = Essential Steps in Managing Obstetric Emergencies.)

SA compared with a significant reduction in direct maternal deaths and especially in severe haemorrhage in the study districts.

The most notable effect of this training was on the management of women with shock (severe haemorrhage) and non-pregnancy-related infections. The management of shock is emphasised during the training, and relatively few factors other than the knowledge and skill of the clinician(s) play a role in its immediate management. Maternal deaths among mothers who had CDs decreased significantly after training; specifically, bleeding during and after $\mathrm{CD}$ was significantly reduced. Specific skills for managing bleeding at $\mathrm{CD}$ are taught during the training. The management of HIV-positive women is fairly uncomplicated with the single-tablet treatment currently used. This simplicity of treatment for HIV-positive women probably contributed to the dramatic drop in mortality due to non-pregnancyrelated infections. In contrast, there are many more health system factors involved in managing cases of severe hypertension, such as the availability of emergency transport, medication and functioning theatre facilities, which may possibly contribute to the non-significant reduction in mortality.

The skills-and-drills emergency obstetric training package has met all the requirements for an effective training package described by Kirkpatrick ${ }^{[9]}$ and explained by Bergh et al. ${ }^{[10]}$ Where the majority of healthcare professionals involved in maternity care had been trained, there was a significant reduction in maternal deaths. However, training alone will not bring about the dramatic reduction in maternal deaths we desire. Health systems strengthening is also needed, as evidenced by the non-significant reduction in maternal deaths due to hypertension. Changes in the health system, such as improving emergency transport or having functioning operating theatres, will help clinicians who have knowledge and skills to use them as effectively as possible to prevent maternal deaths. Initial training, with regular refreshers, should be followed up with supportive supervision and mentoring as part of health systems functioning.

\section{Study strengths and limitations}

The longstanding confidential enquiries into maternal deaths in SA made this before-and-after study possible. The study covered a 6-year period and was based on a robust system of collecting and analysing maternal deaths and a well-described time-bound delivered intervention. The design of the skills-and-drills programme was based on an extensively evaluated emergency obstetric and neonatal care training package. ${ }^{[3,11-15]}$ The scale-up of the skills-and-drills package was supported by a previously tested training programme ${ }^{[2]}$ and was planned according to a stages-of-change model ${ }^{[6]}$ to ensure that all the necessary steps were followed to enable the health system to embrace the training and the changes required. The importance of starting out on a sound footing was acknowledged through an extensive consultation process, followed by written commitment from health authorities to enable employees to be trained. Saturation training requires a robust logistical system that will enable all health professionals to attend the training.

A big scale-up programme has its own challenges and shortcomings. Firstly, it is expensive; it was estimated to be seven times more expensive than on-site training using facilitator-mentors. ${ }^{[16]}$ Extensive logistic support was needed and specific measures had to be put in place to ensure that the delegates attended training. An extensive network of master trainers was needed to conduct the training, and without the support of the clinicians from the LSTM database, it would have been very difficult to provide this. Implementation methods other than off-site training workshops need to be tested to reduce costs.

\section{Conclusions}

A well-structured training programme can improve quality of care and reduce maternal deaths. Building capacity and confidence of healthcare professionals to enable them to work effectively and efficiently to deliver emergency obstetric care can reduce maternal mortality. For optimal effectiveness, complementary changes in the wider health system need to be made.

\section{Declaration. None.}

Acknowledgements. We acknowledge all the master trainers, especially those from the UK who spent two weeks of their holidays helping teach emergency obstetric care. A special thank you goes to Cathy Bezuidenhout (project manager) and Nthabiseng Mokatse, Sidney Mokatse and Danie Thirion (course co-ordinators) for controlling the logistics so well.

Author contributions. RCP, JMo and NvdB conceptualised the study and supervised the implementation. JMa was responsible for monitoring and evaluation and supported statistical analysis. YP facilitated access to health systems and health facilities and was involved in programme design. CA was involved in programme design, monitoring and writing. A-MB provided technical support and was involved in emergency drill activities. RCP and A-MB drafted the initial manuscript, to which all other authors contributed input. All authors approved the final version of the manuscript for submission.

Funding. The study was funded from DFID South Africa (contract no. 200295-102) and DFID Making it Happen (UK) (contract no. 202945101). The funder was not involved in the data analysis or write-up of the article.

Conflicts of interest. None.

Pattinson R, ed. Saving Mothers 2011 - 2013: Sixth Comprehensive Report on the Confidential Enquiries into Maternal Deaths in South Africa. Pretoria: Government Printer, 2016. 
2. Frank K, Lombaard H, Pattinson RC. Does completion of the Essential Steps in Managing Obstetric Emergencies training package improve knowledge and skills in managing obstetric emergencies? S Afr J Obstet Gynaecol 2009;15(3):94-99.

3. Van den Broek N, ed. Life Saving Skills Manual: Essential Obstetric and Newborn Care. 2nd ed. London: Royal College of Obstetricians and Gynaecologists, 2007.

4. Pattinson R, ed. Saving Mothers 2008 - 2010: Fifth Comprehensive Report on the Confidential Enquiries into Maternal Deaths in South Africa. Pretoria: Government Printer, 2012.

5. Pattinson RC, Bergh A-M, Makin J, Pillay Y, Moodley J, Ameh C, et al. Knowledge and skills training as a catalyst for change. S Afr Med J 2018;108(9):748-755. https://doi.org/10.7196/SAMJ.2018. v108i9.13073

6. Bergh A-M, Allanson E, Pattinson R. What is needed for taking emergency obstetric and neonatal programmes to scale? Best Pract Res Clin Obstet Gynaecol 2015;29(8):1017-1027. https://doi. org/10.1016/j.bpobgyn.2015.03.017

7. Pattinson RC, Makin JD, Pillay Y, van den Broek N, Moodley J. Basic and comprehensive emergency obstetric and neonatal care in 12 South African health districts. S Afr Med J 2015;105(4):256-260. https://doi.org/10.7196/SAMJ.9181

8. Pattinson R, ed. Saving Mothers 2014 - 2016: Seventh Report on Confidential Enquiries into Maternal Deaths in South Africa. Pretoria: Government Printer, 2017.

9. Kirkpatrick D. Evaluating Training Programs: The Four Levels. 2nd ed. San Francisco: Berrett-Kochler Publishers, 1998.

10. Bergh A-M, Baloyi S, Pattinson R. What is the impact of multi-professional emergency obstetric and neonatal care training? Best Pract Res Clin Obstet Gynaecol 2015;29(8):1028-1243. https://doi. org/10.1016/j.bpobgyn.2015.03.017
11. Ameh A, van den Broek N. Making it happen: Training healthcare providers in emergency obstetric and newborn care. Best Pract Res Clin Obstet Gynaecol 2015;29(8):1077-1091. https://doi. obstetric and newborn care. Best
org/10.1016/j.bpobgyn.2015.03.019

12. Ameh C, Bishop S, Kongnyuy E, Grady K, van den Broek N. Challenges to the provision of emergency obstetric care in Iraq. Matern Child Health J 2011;15(1):4-11. https://doi.org/10.1007/s10995-009-0545-3 13. Grady K, Ameh C, Adegoke A, Kongnyuy E, Dornan J, Falconer T. Improving essential obstetric and . Grady K, Ameh C, Adegoke A, Kongnyuy E, Dornan J, Falconer T. Improving essential obstetric and
newborn care in resource-poor countries. J Obstet Gynaecol 2011:31(1):18-23. https://doi.org/10.310 newborn care in resource-poor countries. J Obstet Gynaecol 2011;31(1):18-23. https://doi.org/10.31 9/01443615.2010.533218

14. Ameh C, Adegoke A, Hoffman J, Ismail FM, Ahmed FM, van den Broek N. The impact of emergency obstetric care training in Somaliland, Somalia. Int J Gynecol Obstet 2012;117(3):283-287. https://doi. org/10.1016/j.ijgo.2012.01.015

5. Ameh C, Kerr R, Madaj B, et al. Knowledge and skills of healthcare providers in sub-Saharan Africa and Asia before and after competency-based training in emergency obstetric and early newborn care. PloS One 2016;11:e0167270. https://doi.org/10.1371/journal.pone.0167270

16. Bezuidenhout CM, Makin JD, Pattinson RC. Scaling up of ESMOE in South Africa: What is it going to cost and what type of training are we going to use? Proceedings of the 33rd Conference on Priorities in Perinatal Care in South Africa, Cape Town, South Africa, 11 - 14 March 2014. https://www: perinatalpriorities.co.za/proceedings-database/ (accessed 16 July 2018).

Accepted 7 September 2018 